\title{
Evaluating Mawared as a self-service quality information system at Prince Sattam bin Abdulaziz University using Dillon and McLean model
}

\author{
Saeed Ali Omer Bahaj \\ Department of Management Information System, College of Business Administration, Prince Sattam bin Abdulaziz University. \\ Email: s.bahaj@psau.edu.sa
}

\begin{abstract}
Quality of information system is reviewed by many as critically important for most if not all organizations to review their return on their investment in information system (IS) technology. Currently, there are numerous works of literature addressing factors or techniques for measuring system quality - business benefits, user satisfaction, or usage among others. This paper is evaluating the quality of information systems- self-services (Mawared) at Prince Sattam Bin Abdulaziz University (PSAU) using the Dillon and McLean Model. Intrinsically, information systems (IS) vary depending on the industry they are applied, for example, in this research, the IS under review as an educational-based information system. This paper aims to explore the relationships of information system quality and its main outcomes which are expected or were proposed for the IS. Subsequently, this paper focuses on the self-service information system, its quality. The research uses questionnaires for its research methodology that are distributed out to the faculty members in College of Business Administration at PSAU. The findings of this study indicate to a positive and high degrees of satisfaction among the faculty members towards Mawared as a self-service quality information system for the academic year 2020-2021. Moreover, it provides new insights into the efficacy of selected determines of information system quality and user satisfaction.
\end{abstract}

Keywords:

Quality information system, user satisfaction, Mawared, PSAU.

Article Received: 18 October 2020, Revised: 3 November 2020, Accepted: 24 December 2020

\section{Background of the study}

Today, most industries rely on one or more information system (IS). As such, enterprises are striving to acquire one or more varieties of information systems (IS) to take advantage of the opportunities and strengths that they offer. For example, these systems assist in enhancing and accelerating the completion of tasks and offer a competitive edge as well as help an organization achieve its desired future state as well as its goals. As more organizations continue to depend on information systems, there is an urgency of for evaluating their quality and services either by reviewing the services or outputs or the system elements. An example a common IS is the management information system (MIS) which is a set of information interconnected concerning an organization management processes and enhance management service delivery. The aim is to streamline information collection, storage, processing, presentation to help to offer better information for better decision making.
Intrinsically, before designing or adopting an information system is it important to evaluate its quality. As such, information system quality can be determined by the value that the IS service brings to both its users and organization, however, IS quality is not measured in most organizations today. Moreover, IS' are human-made - they are designed to think and enhance our everyday lives through the automation of both elementary and complex processes (Cater-Steel \& Lepmets, 2014). Laudon and Laudon (2015) contend that management information systems (MIS) are the integration of human resources, information technology, and management models that work as one system to gather, store, process, and distribute information in an orderly and compatible manner to enhance the decision-making process. O Brien (201) affirms that MIS is the orderly integration of human resources, information technology, management strategies, business processes, data, data sources, and risk management to enhance data 
collection, processing, storage, retrieval, and presentation in a more efficient manner.

Information system is more than hardware and software, it includes human resources and strategic business model. Though it has numerous components, making them work together as one unit is what distinguishes them from other systems. As information becomes the core of every industry, information management is crucial in all aspects not only on a corporate level. According to Rosebaum (2019), world-wide IT and information security spending by the end of 2019 was 4 trillion dollars, this shows the extent organizations are willing to go to enhance their information management. This shows that data has become one of the most crucial assets not only for organizations but everyone. O'Dea (2020) contends that by 2021 the IT spending will have grown by 4.3 per cent. However, not each IS should be adopted, the deployment of depends on what it is meant for, while its success can be evaluated through reviewing user satisfaction.

Published in 1992, the DeLone \& Mclean model is a comprehensive review of IS success and provides one of the most robust models for evaluating information systems. As a framework, the model offers a way of measuring the complexdependent variable of information system research. As mentioned before, this research reviews how to evaluate the quality of an information system through some of the world's best-known models. Moreover, DeLone and McLean reviewed some of the best definition of IS success, corresponding measures, and classification through six major categories. Thus, they modelled the multidimensional framework measuring model for the affiliations between success criteria. Though the DeLone \& McLean IS Success Model attempts to offer a comprehensive view on IS success, there has been extensive research on the success dimensions that vary from organization to organization.

As mentioned, in this section, the DeLone \& McLean IS Success Model includes six main categories. The first is the system quality category, that constitutes desirable features of an information system (IS) success dimension. This evaluation criterion focuses on usability aspects and performance characteristics - ease of use. The second evaluation criterion is the information quality; this is the measure of an IS output. The output quality is crucial for any IS success. Thirdly, is service quality, the quality of service IS users receive. Fourth is the intention of use, how the IS will or are being used. The fifth is user satisfaction, the main feature and success evaluation of any IS, this is useful when reviewing the mandatory usage of an information system. Sixth is the net benefits evaluation dimension, that means reviewing the return on investment for IS stakeholders. Though user satisfaction and use are correlated with net benefits, there is a necessity to measure net benefits unswervingly.

This research seeks to evaluate the Mawared as a self-service quality system quality among faculty members in College of Business Administration at Prince Sattam bin Abdulaziz University. Furthermore, it focuses on verifying the proposed model (DeLone \& McLean IS Success Model) on the findings of this research ensuring validity and reliability for use in a broader setting.

The remaining of the paper is organized as follows. Section 2 highlights the research methodology. Section 3 shows the results and discussions and the final section, 4 , concludes the study.

\section{Research Methodology}

This study uses the survey methodology with a target of 60 respondents. The survey is selfadministrative which is adopted and adapted from the DeLone \& McLean IS Success Model for academic review. The questionnaire includes two main sections, A and B, Section A comprising of five demographic variables while Section B compromising of 11 statements designed to evaluate the satisfaction degree of the faculty members in College of Business Administration at PSAU towards Mawared as a self-service quality information system. Section B statements were 
measured using a five-point Likert scale to make it easy for respondents to complete the questionnaire providing near accurate information. The respondents' agreement ranges from " 1 " strongly agree to " 5 " strongly disagree. Moreover, the study focused on 50 College of Business Administration faculty members. Fifty of the sixty respondents returned usable results that were used for the research analysis, indicating to $83 \%$ responding rate.

\section{Results and Discussions}

\section{Descriptive Statistics}

Table 1 and figures from 1 to 5 summarize the demographic information of the respondents.

Table 1: Demographic Attributes of the respondents

\begin{tabular}{lcc}
\hline Demographic characteristics & Frequency $(\mathbf{n}=\mathbf{5 0})$ & Percent $\%$ \\
\hline Gender & 39 & 78 \\
\hline Male & 11 & 22 \\
\hline Female & 7 & 14.0 \\
\hline Age & 18 & 36.0 \\
\hline between 18-27 & 20 & 40.0 \\
\hline $28-35$ & 5 & 10.0 \\
\hline $36-45$ & & 14.0 \\
\hline 45 an above & 7 & 38.0 \\
\hline Work experience & 19 & 2.0 \\
\hline Less than one & 1 & 46.0 \\
\hline $1-3$ & 23 & 24.0 \\
\hline $4-7$ & & 16.0 \\
\hline more than 7 years & 12 & 24.0 \\
\hline Specialization & 8 & 16.0 \\
\hline MIS & 12 & 14.0 \\
\hline Finance & 8 & 2.0 \\
\hline Accounting & 7 & 4.0 \\
\hline Management & 1 & 8.0 \\
\hline HRM & 2 & 26.0 \\
\hline Marketing & & 64.0 \\
\hline Law & 4 &
\end{tabular}

HRM refers to Human Resource Management

** MIS refers to Management Information System 


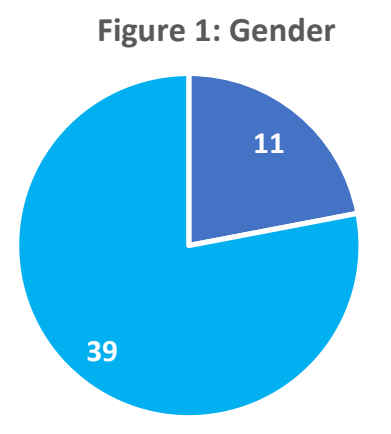

$$
\text { - Female - Male }
$$

Figure 3: Work experience

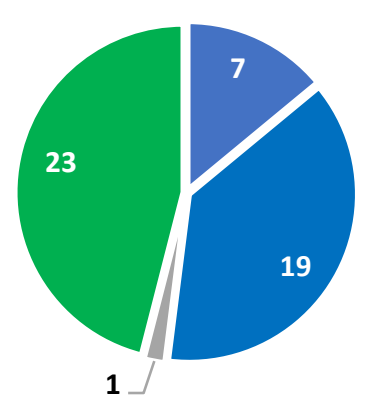

- Less than one $\mathbf{~ 3 - J a n ~} \boldsymbol{- 7 - A p r}$ - more than 7 years
Figure 2: Age

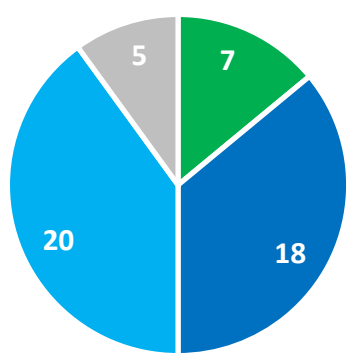

- between 18-27 - 28-35 - 36-45 - 45 an above

Figure 4: Academic Qualification

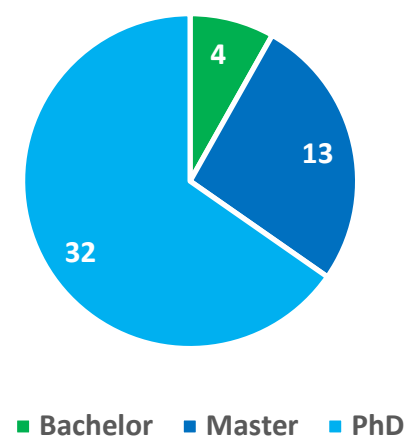

Figure 5: Specialization

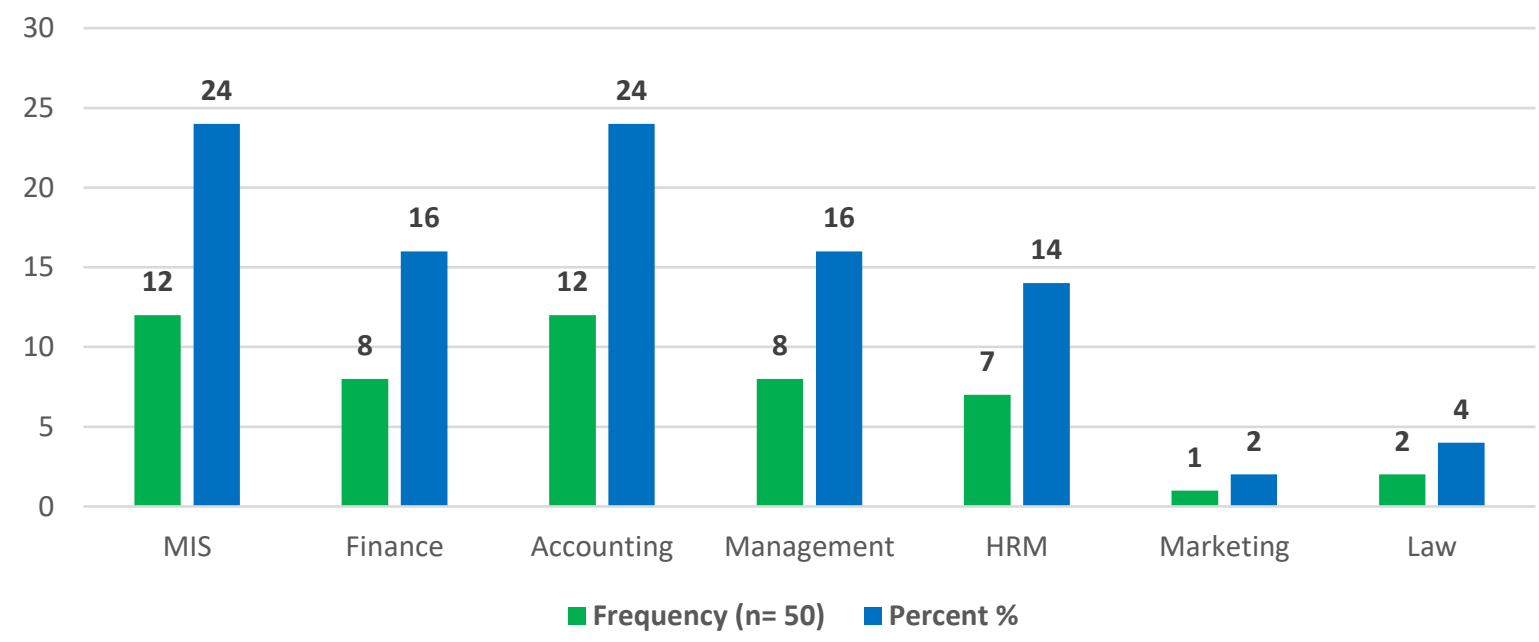

Table 1 and figure 6 show that $78 \%$ of the respondents was male and $22 \%$ was female. In terms of the age, the majority of the respondents were aged between 36-45. As for the work experience, $46 \%$ of the respondents have more than
7 years working experience. The majority of the respondents were accounting specialized faculty members. With regard to the academic qualification, $64 \%$ of the respondents holds a doctorate degree. 
Table 2. Descriptive statistics

\begin{tabular}{|c|l|c|c|c|c|}
\hline No. & \multicolumn{1}{|c|}{ Statements } & Minimum & Maximum & Mean & $\begin{array}{c}\text { Std. } \\
\text { Deviation }\end{array}$ \\
\hline 1 & Mawared is easy to use & 1 & 3 & 1.72 & .497 \\
\hline 2 & $\begin{array}{l}\text { Mawared is easy to be modified according to our needs and } \\
\text { deal with }\end{array}$ & 1 & 4 & 2.40 & .926 \\
\hline 3 & Mawared makes information easy to access and interact & 1 & 4 & 1.92 & .601 \\
\hline 4 & Mawared responds quickly to my request & 1 & 4 & 1.92 & .601 \\
\hline 5 & $\begin{array}{l}\text { Information extracted from Mawared is well formatted and } \\
\text { clearly presented on the screen }\end{array}$ & 1 & 6 & 2.30 & .839 \\
\hline 6 & The information provided by Mawared is always updated & 1 & 7 & 2.16 & 1.131 \\
\hline 7 & Mawared provides me with information relevant to my work & 1 & 5 & 1.84 & .710 \\
\hline 8 & $\begin{array}{l}\text { Mawared reduces the time required to accomplish tasks at } \\
\text { the university }\end{array}$ & 1 & 8 & 1.88 & 1.081 \\
\hline 9 & Mawared improves the quality of our work & 1 & 9 & 2.14 & 1.178 \\
\hline 10 & Mawared outputs are high accuracy and free from errors & 1 & 10 & 2.50 & 1.313 \\
\hline 11 & Overall, I am satisfied with Mawared & 1 & 11 & 1.96 & 1.428 \\
\hline
\end{tabular}

Figure 6: Mean of respondents

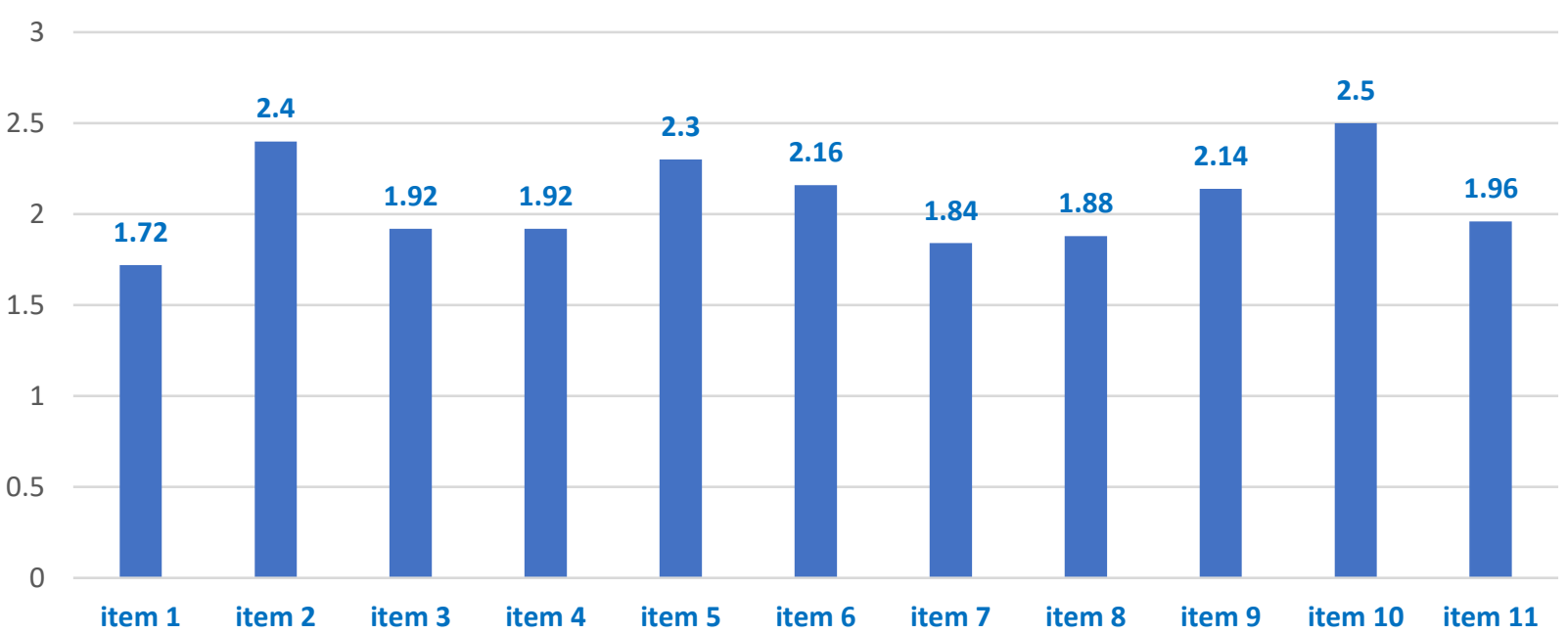

Table 2 shows that the respondents' satisfaction ranges between the mean of 1.72 and 2.50. This indicates that there is a positive attitude towards Mawared as a self-service quality information system. The respondents' perception towards
Mawared ranges from high degree of satisfaction to a high moderate degree of satisfaction. This result indicates that PSAU's Mawared as a selfservice quality information system is useful for faculty members.

Table 3. mean and value of the statements

\begin{tabular}{|c|l|c|c|}
\hline No. & \multicolumn{1}{|c|}{ Statements } & Mean & Value \\
\hline 1 & Mawared is easy to use & 1.72 & High \\
\hline 2 & Mawared is easy to be modified according to our needs and deal with & 2.40 & High \\
\hline 3 & Mawared makes information easy to access and interact & 1.92 & High \\
\hline 4 & Mawared responds quickly to my request & 1.92 & High \\
\hline
\end{tabular}




\begin{tabular}{|c|l|c|c|}
\hline 5 & $\begin{array}{l}\text { Information extracted from Mawared is well formatted and clearly presented on } \\
\text { the screen }\end{array}$ & 2.30 & High \\
\hline 6 & The information provided by Mawared is always updated & 2.16 & High \\
\hline 7 & Mawared provides me with information relevant to my work & 1.84 & High \\
\hline 8 & Mawared reduces the time required to accomplish tasks at the university & 1.88 & High \\
\hline 9 & Mawared improves the quality of our work & 2.14 & High \\
\hline 10 & Mawared outputs are high accuracy and free from errors & 2.50 & moderate \\
\hline 11 & Overall, I am satisfied with Mawared & 1.96 & High \\
\hline
\end{tabular}

Table 3 depicts that almost all of the respondents indicated to a positive attitude towards Mawared as a self-service quality information system. This obviously appears in the values of the statements measuring the level of the respondents' agreements towards Mawared. The respondents indicate to a high degree of satisfaction to all the statements except statement no. 10 stating that "Mawared outputs are high accuracy and free from errors" which is given a moderate degree of satisfaction.
Still statement no. 10 is considered a positive satisfaction toward Mawared although it is ranked as a moderate.

\section{Regression results}

The dependent and independent variables examined in this study were tested using multiple regression as shown in the following Tables 4, 5, and 6.

Table 4: Model Summary

\begin{tabular}{ccccc}
\hline Model & R & R Square & Adjusted R Square & Std. Error of the Estimate \\
\hline $\mathbf{1}$ & $.586 \mathrm{a}$ & .343 & .265 & .32130
\end{tabular}

Table 4 shows that the coefficient of determination $\left(\mathrm{R}^{2}\right)$ for the model is equal to 26.1 per cent which means that all the variables accounted for $26.5 \%$ of the variance in model.

Table 5: ANOVA

\begin{tabular}{cccccc}
\hline Model & $\begin{array}{c}\text { Sum of } \\
\text { Squares }\end{array}$ & df & Mean Square & F & Sig. \\
\hline Regression & 2.263 & 5 & .453 & 4.385 & .003 \\
\hline Residual & 4.336 & 42 & .103 & & \\
\hline Total & 6.599 & 47 & & & \\
\hline
\end{tabular}

Table 5 depicts that the model is a statistically significant where the $F$ test statistic $=4.385$ with a p-value < 0.000 .

Table 6: Coefficients

\begin{tabular}{|c|c|c|c|c|c|c|c|}
\hline \multirow[t]{2}{*}{ Model } & \multicolumn{2}{|c|}{$\begin{array}{l}\text { Unstandardized } \\
\text { coefficients }\end{array}$} & \multirow{2}{*}{$\begin{array}{c}\text { Standardized } \\
\text { Coefficients }\end{array}$} & \multirow[t]{2}{*}{$\mathrm{t}$} & \multirow[t]{2}{*}{ Sig. } & \multicolumn{2}{|c|}{$\begin{array}{c}\text { Collinearity } \\
\text { Statistics }\end{array}$} \\
\hline & B & Std. Error & & & & Tolerance & VIF \\
\hline (Constant) & 1.634 & .228 & & 7.175 & .000 & & \\
\hline Gender & -.222 & .134 & -.252 & $\begin{array}{c}- \\
1.655\end{array}$ & .105 & .675 & 1.482 \\
\hline Age & .376 & .087 & .854 & 4.344 & .000 & .405 & 2.471 \\
\hline
\end{tabular}




\begin{tabular}{lccccccc}
\hline Work experience & -.025 & .046 & -.078 & -.536 & .595 & .738 & 1.354 \\
\hline Specialization & -.107 & .037 & -.476 & - & .006 & .574 & 1.741 \\
\hline $\begin{array}{l}\text { Academic } \\
\text { qualification }\end{array}$ & -.147 & .100 & -.253 & $\begin{array}{c}- \\
1.461\end{array}$ & .151 & .521 & 1.920 \\
\hline
\end{tabular}

Table 6 shows that age is related positively to the usage of Mawared information system $(p>0.01)$ and the specialization is related negatively to the usage of Mawared information system $(p>0.01)$

\section{Conclusion}

The focus of this study is to examine the faculty members' level of satisfaction towards Mawared as a self-service quality information system. The target sample of this study was faculty members in College of Business Administration at Prince Sattam bin Abdulaziz University for the academic year 2020-2021. This study is a survey-based methodology applying DeLone \& McLean IS Success Model with an adaptation. The results of this study indicate that faculty members in College of Business Administration have a positive attitude towards Mawared as a self-service quality information system. This high level of satisfaction indicates that Mawared is a useful information system for the faculty members to be used for their self-service.

\section{Acknowledgement}

The author would like to thank Prince Sattam bin Abdulaziz University for sponsoring and supporting the preparation and publication of this research paper throughout the "Specialized Research Grant Program" under the Research Number 2020/02/17152. I would like also to express my utmost appreciation to the Dean of Deanship of Scientific Research (DSR) and the staff in the DSR for their kindness and assistance during the process of conducting this research.

\section{Reference}

[1] Delone, W. H., \& McLean, E. R. (2003). The DeLone and McLean model of information systems success: a ten-year update. Journal of management information systems, 19(4), 9-30.
[2] Jaafreh, A. B. (2017). Evaluation information system success: Applied delone and McLean information system success model in context banking system in KSA. International Review of Management and Business Research, 6(2), 829-845.

[3] Jaafreh, A. B. (2017). Evaluation information system success: Applied delone and McLean information system success model in context banking system in KSA. International Review of Management and Business Research, 6(2), 829-845.

[4] Laudon, K. C., \& Laudon, J. P. (2015). Management information systems. Upper Saddle River: Pearson.

[5] O'Brien, James A., (2004), Information system management, Tata McGraw Hill, New Delhi

[6] Palmius, J. (2007). Criteria for measuring and comparing information systems.

[7] Petter, S., \& McLean, E. R. (2009). A metaanalytic assessment of the DeLone and McLean IS success model: An examination of IS success at the individual level. Information \& Management, 46(3), 159-166.

[8] Petter, S., DeLone, W., \& McLean, E. (2008). Measuring information systems success: models, dimensions, measures, and interrelationships. European journal of information systems, 17(3), 236-263.

[9] Zaied, A. N. H. (2012). An integrated success model for evaluating information system in public sectors. Journal of 
Emerging Trends in Computing and Information Sciences, 3(6), 814-825.

[10] Zaied, A. N. H. (2012). An integrated success model for evaluating information system in public sectors. Journal of Emerging Trends in Computing and Information Sciences, 3(6), 814-825. 